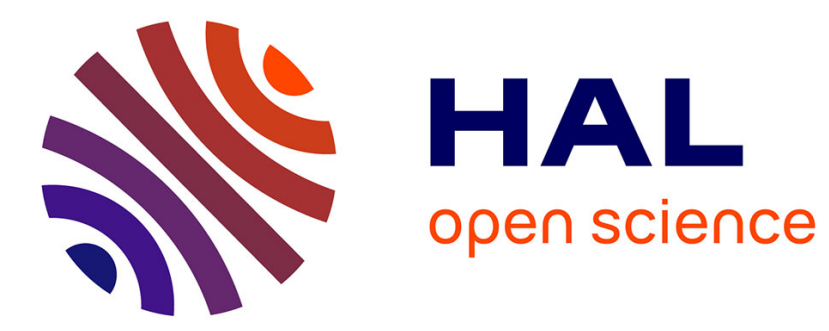

\title{
Controlling nucleation and growth of nano-CaCO 3 via CO 2 sequestration by a calcium alkoxide solution to produce nanocomposites for drug delivery applications
}

N. G. Martin Palmqvist, Jean-Marie Nedelec, Gulaim A. Seisenbaeva, Vadim G. Kessler

\section{To cite this version:}

N. G. Martin Palmqvist, Jean-Marie Nedelec, Gulaim A. Seisenbaeva, Vadim G. Kessler. Controlling nucleation and growth of nano-CaCO 3 via $\mathrm{CO} 2$ sequestration by a calcium alkoxide solution to produce nanocomposites for drug delivery applications. Acta Biomaterialia, 2017, 57, pp.426 - 434. 10.1016/j.actbio.2017.05.006 . hal-01613346

\section{HAL Id: hal-01613346 https://hal.science/hal-01613346}

Submitted on 8 Feb 2022

HAL is a multi-disciplinary open access archive for the deposit and dissemination of scientific research documents, whether they are published or not. The documents may come from teaching and research institutions in France or abroad, or from public or private research centers.
L'archive ouverte pluridisciplinaire HAL, est destinée au dépôt et à la diffusion de documents scientifiques de niveau recherche, publiés ou non, émanant des établissements d'enseignement et de recherche français ou étrangers, des laboratoires publics ou privés. 
Full length article

\title{
Controlling nucleation and growth of nano- $\mathrm{CaCO}_{3}$ via $\mathrm{CO}_{2}$ sequestration by a calcium alkoxide solution to produce nanocomposites for drug delivery applications
}

\author{
N.G. Martin Palmqvist ${ }^{a}$, Jean-Marie Nedelec ${ }^{\mathrm{b}, *}$, Gulaim A. Seisenbaeva ${ }^{\mathrm{a}}$, Vadim G. Kessler ${ }^{\mathrm{a}, *}$ \\ ${ }^{a}$ Department of Chemistry and Biotechnology, SLU BioCenter, Box 7017, 75007 Uppsala, Sweden \\ ${ }^{\mathrm{b}}$ Université Clermont Auvergne, CNRS, SIGMA Clermont, ICCF, F-63000 Clermont-Ferrand, France
}

\section{A R T I C L E I N F O}

\section{Article history:}

Received 27 February 2017

Received in revised form 18 April 2017

Accepted 3 May 2017

Available online 5 May 2017

\section{Keywords:}

Calcite nanoparticles

Nanocomposites

Encapsulation matrix

Stable aqueous hydrophobic colloids

\begin{abstract}
A B S T R A C T
Calcium carbonate is an extremely attractive material in a plethora of biomedical applications. Intensive efforts have recently been made to achieve the control over its nucleation and subsequent aggregation, growth and crystallization; focusing on bringing insight into the role of precursors, solvents and templates. Having analyzed the recently acquired knowledge, we addressed this challenge using $\mathrm{CO}_{2}$ sequestration synthesis, using an unusual reactant, a solution of calcium ethoxide, $\mathrm{Ca}\left(\mathrm{OC}_{2} \mathrm{H}_{5}\right)_{2}$, as precursor. By tailoring the reaction conditions, it was possible to produce extremely small and rather size-uniform single-phase calcite $\mathrm{CaCO}_{3}$ nanoparticles, forming sols and subsequently gels in the applied medium. According to DLS and nanoparticle tracking analysis the particles are only to a minor extent aggregated in the mother liquor and can form transparent gels on concentration in less polar media, but produce large aggregates $400-800 \mathrm{~nm}$ in size when dried and subsequently transferred to aqueous media. Complete drying of solutions renders xerogel type materials with only moderate active surface area, as identified by nitrogen adsorption, due to aggregation with development of densified surface layers. Such behaviour is typical for the sol-gel synthesis of particles possessing enhanced surface reactivity. The aggregation on drying was used to produce hybrid nanocomposites, with the hydrophobic model component, $\beta$-carotene, introduced in solution in a non-polar co-solvent and model medicine - ibuprofen. The obtained nanocomposite particles, characterized by SEM, TEM, XRD, AFM and FTIR studies, are hierarchically structured spheroidal aggregates about $200 \mathrm{~nm}$ in size with uniform distribution of the organic components present in the amorphous state. The composite particles are stable in neutral aqueous environments but are readily dissolved in acidic medium or even in PBS at $\mathrm{pH}=7.40$, releasing the hydrophobic organic component in the form of a relatively stable colloid solution. Efficient release of ibuprofen as model drug was achieved in both acidic and PBS medium and could be slowed down by the addition of $\beta$-carotene as hydrophobic component.
\end{abstract}

\section{Statement of Significance}

The proposed sol-gel synthesis of $\mathrm{CaCO}_{3}$ proved to create unprecedented size of $\mathrm{CaCO}_{3}$ nanoparticles with striking size uniformity. The obtained results clearly demonstrate their ability to incorporate hydrophobic components in a nanocomposite matrix converting them into amorphous nano sized particles, building stable colloids via release in acidic medium. Transfer of a sol produced in organic medium into water in the presence of albumen surfactant results in relatively uniform micro particles about $1 \mu \mathrm{m}$ size. The obtained materials show characteristics attractive for use in drug delivery and potentially also a variety of other industrial applications.

(c) 2017 Acta Materialia Inc. Published by Elsevier Ltd. All rights reserved.

\footnotetext{
* Corresponding author.

E-mail addresses: jean-marie.nedelec@sigma-clermont.fr (J.-M. Nedelec), Vadim. Kessler@slu.se (V.G. Kessler).
}

\section{Introduction}

Calcium carbonate, $\mathrm{CaCO}_{3}$, is today one of the absolutely most addressed nano materials in the view of its extensive applications 
for drug delivery [1-15] and even tissue engineering applications [16]. The attractive feature of this material is that it remains poorly soluble in neutral or basic media but rapidly dissolves in acidic ones, including cytosol $(\mathrm{pH}=5.5)$ opening for specific release on uptake into the cells. Very intensive focus in these studies is set on bringing understanding into the mechanisms of nucleation as the step determining further reactivity towards aggregation, crystallization and growth as it is the size of the particles and their crystallinity and surface energy that define their further solubility. Direct high resolution microscopic observations are very much in favour of classic ion clustering mechanisms [17], supported by theoretical modelling [18-20]. It has been noticed, however, that nonclassical nucleation mechanisms influenced by the nature of precursor species can in fact be a parallel track [17,21]. The aim in these recent studies was in the first hand to understand how the process can be directed towards smaller primary particles, which, even if not being crystalline, are displaying a well-developed short order structure [18], and how they in turn transform into nano and bulk materials $[17,20]$.

Different polymorphs of $\mathrm{CaCO}_{3}$ usually crystallize into fine powders consisting of micrometre sized particles, and calcite, aragonite and vaterite phases can be produced by changing the ratio and mixing rate of the precursor salts, $\mathrm{pH}$ and reaction temperature [22]. Numerous investigations of production of small particles through nucleation show that in aqueous media, where $\mathrm{CaCO}_{3}$ is relatively soluble, the major obstacle is presented by the Ostwald ripening $[17,21]$. This process is associated with dissolution of the smallest particles with highest surface energy and the mass transfer to the bigger ones, resulting in polydispersity and increase in particle size [23]. It is thus, a process that needs to be prevented in order to keep particle size as small and uniform as possible. For this purpose, it is important to reduce the solubility of the nucleating salt or mobility of its constituent ions. This can be achieved in a plethora of ways from cooling the solution medium, adding spectator ions, adding a surfactant or biomolecular template (which have received special attention in case of $\mathrm{CaCO}_{3}$ ) [24], evaporating solvent or changing solvent [25-28]. Also physical chemical approaches with thorough control of stirring, addition and mixing of reactants have been evaluated [29-38]. However these methods usually lead to quite poly-disperse particles and to the best of our knowledge never with particle size below $20 \mathrm{~nm}$. Most promising for further diminution of the particle size have recently been proposed to be, on one hand, the addition of smaller and higher charged ions [39], causing enhanced surface charge of the particles, and, on the other hand, the uptake of carbon dioxide gas by solution of calcium organic derivatives in less polar medium [40]. For the latter approach, we considered the precursor calcium ethoxide most promising, since it immediately transforms on contact with humid atmosphere into large oligo-nuclear oxo-ethoxide species, like $\mathrm{Ca}_{6} \mathrm{O}_{2}\left(\mathrm{OC}_{2} \mathrm{H}_{5}\right)_{8}\left(\mathrm{C}_{2} \mathrm{H}_{5} \mathrm{OH}\right)_{14}$ [41], and is potentially capable of facilitating the nucleation process, according to theoretical predictions [7]. This state-of-the-art method produces unprecedented sizes of calcite nano crystals and will be of interest for development of drug delivery matrices, composite materials and paper products.

\section{Materials and methods}

\subsection{Synthesis}

\subsubsection{Standard precipitation method}

Under stirring at $1600 \mathrm{rpm}$ with Selecta agimatic-N, $200 \mathrm{ml}$ of calcium bromide $\left(\mathrm{CaBr}_{2}\right.$ from Sigma Aldrich Ref. 71626-99-8) $0.01 \mathrm{M}$ solution was added dropwise into $100 \mathrm{ml}$ of ammonium carbonate $\left(\mathrm{NH}_{4}\right)_{2} \mathrm{CO}_{3}$ from Janssen Chemicals Ref. 506-87-6)
$0.02 \mathrm{M}$ solution. Two additional versions of the precipitation method were investigated by adding the dopants, magnesium or iron (III) cations or both these cations together with albumen as surfactant (Whole egg whites from Svenska Lantägg) into the $\mathrm{CaBr}_{2}$-solution. Magnesium chloride tetra hydrate $\left(\mathrm{MgCl}_{2}\left(\mathrm{H}_{2} \mathrm{O}\right)_{4}\right.$ from Merck Ref. 5833) was added in 2:1 ratio with respect to Ca and iron trichloride $\left(\mathrm{FeCl}_{3}\right.$ from Merck Ref. 231-729-4) was added $1: 1$ with respect to $\mathrm{Ca}$. One volume percent of albumen, in respect to the final volume of $300 \mathrm{ml}$, was added to the $\left(\mathrm{NH}_{4}\right)_{2} \mathrm{CO}_{3}$ solution. The resulting aqueous dispersions were analysed by Nanoparticle Tracking Analysis (NTA) and dried samples also by scanning transmission microscopy (SEM) and X-ray diffraction (XRD).

\subsubsection{Gas-solid precipitation method}

The gas-solid approach was a method modified from Baroum et al. [35]. Calcium oxide ( $\mathrm{CaO}$ from Mallinckrodt Ref. 4243) was first calcined at 800 degrees to remove any possible carbonates. While still hot the $\mathrm{CaO}$ was transferred to an e-flask with milli-Q water and the suspension was heated to the boiling point before filtering it through Munktell grade 5 filter paper. Later the super saturated solution of calcium hydroxide $\left(\mathrm{Ca}(\mathrm{OH})_{2}\right)$ was injected with carbon dioxide $\left(\mathrm{CO}_{2}\right)$ gas under vigorous, at a flow speed of $200 \mathrm{ml} \mathrm{min}^{-1}$ at 50 Bar. A pH-meter was used to monitor the reaction and the addition of $\mathrm{CO}_{2}$ was stopped after $\mathrm{pH}$ stabilized between six and seven, after approximately ten to fifteen minutes.

\subsubsection{Sol-gel method}

Solid calcium (Ca from Sigma Aldrich Ref. 1001372965) was left to react on low heating temperature (about $40^{\circ} \mathrm{C}$ ) with dry ethanol for $24 \mathrm{~h}$ under dry nitrogen atmosphere. When the Ca metal had reacted to produce calcium ethoxide the solution was removed, by decantation, from residual lumps of oxidized calcium. The milky homogenous solution of approximately $500 \mathrm{mg} / 100 \mathrm{ml}$ was brought into contact with ambient atmosphere and carbon dioxide $\left(\mathrm{CO}_{2}\right.$ from AGA Ref. 109828) was bubbled through at a flow rate of $200 \mathrm{ml} \mathrm{min}^{-1}$ with 50 bar pressure. The $\mathrm{pH}$ was monitored under the whole process and the flow of $\mathrm{CO}_{2}$ was stopped when the $\mathrm{pH}$ stabilized around neutral to slightly acidic level after approximately ten to fifteen minutes. A variation of the method was made to incorporate $\beta$-carotene (from Sigma Aldrich Ref. 101644488) into the $\mathrm{CaCO}_{3}$. Before $\mathrm{CO}_{2}$ was injected, $7.0 \mathrm{ml}$ of $\beta$ - carotene in toluene (from VWR Ref. 28676.366) 7.5 mM was added to the calcium ethoxide solution. For preparation of a composite containing ibuprofen $5.0 \mathrm{ml}$ of ethanol solution containing $100 \mathrm{mg}$ of the medicine were added to a standard synthesis batch, resulting in a composite with 0.025 wt.\% of the ibuprofen.

\subsection{Materials characterization}

The $\mathrm{CaCO}_{3}$ hydrodynamic size was studied by nano tracking analysis on the Malvern NS300. Crystallinity and crystallite size was investigated with powder X-ray Diffraction (XRD) on a Bruker smart APEX-II multipurpose diffractometer using $\mathrm{MoK}_{\alpha}$-radiation with $\lambda 0.71073 \mathrm{~nm}$. Crystallite sizes were calculated using Sherrer equation:

\section{$\mathrm{t}=\mathrm{K} \lambda / \beta \cos \theta$}

With a $\mathrm{K}$ of 0,89 on the most intense peak around 2 theta angle 13 degrees. A Zeiss 1550 Schottky field emission scanning electron microscope (SEM) with silicon drift energy dispersive X-ray detector was used to image the materials and perform elemental analysis. A table top ESEM Hitachi TM-1000 was used for imaging and elemental analysis with Oxford $\mu$-DeX. High Resolution Transmission electron microscopy (HRTEM) was carried out on a Philips CM-20 Super Twin operating at $200 \mathrm{keV}$ and on a FEI Tecnai F30 ST operating at $300 \mathrm{keV}$ both with Gatan Digital Micrograph soft- 
ware. Particles were dispersed in ethanol by sonication for three minutes before being dropped onto carbon coated 300 mesh copper grids. Particles were measured using Image-J on the acquired DM3 files or DM4 files. Material composition was investigated with thermogravimetric analysis (TGA) on a Perkin-Elmer Pyris 1 instrument under oxygen atmosphere. Fast Fourier transform infrared spectroscopy (FTIR) was performed on a Perkin Elmer Spectrum 100 in potassium bromide pellets. Textural characteristics (specific surface area, mean pore size, porous volume) were measured using nitrogen sorption at $77 \mathrm{~K}$ on a Quantachrome Autosorb 1 apparatus. Dynamic light scattering (DLS) and Zeta potential were measured on a Malvern Nano S instrument. Surface structure was characterized using Bruker FastScan Bio Atomic Force Microscopy (AFM) instrument operating in tapping mode.

\subsection{Release tests}

To measure the release of $\beta$-carotene from the drug loading matrix the powder was carefully measured with a balance and placed in glass cylinders with milli-q water as control or hydrochloric acid $(\mathrm{HCl}) \quad 0.1 \mathrm{M}$ to simulate stomach conditions. The powder was mixed into suspension through sonication before toluene was carefully added on top of the liquid. Separate samples, kept in a fridge for darkness and cold, were measured at different time points and two versions of the experiment were performed, one where the cylinders were vortexed at the time point before measurements and one where the dissolution and transfer toward the toluene was allowed to proceed spontaneously. The amount of carotene dissolved in toluene was measured spectrophotometrically at wavelength $451 \mathrm{~nm}$. Time lapse experiment, showing the release and aggregation, of the resulting nano $\beta$-carotene was also performed.

Ibuprofen release was investigated both from pure $\mathrm{CaCO}_{3}$ and from the composite containing $2 \mathrm{wt} \%$ of $\beta$-carotene with molar mass $536.89 \mathrm{~g} / \mathrm{mol}$. In a typical experiment $0.79 \mathrm{~g}$ of the composite were set under continuous stirring in contact with $40 \mathrm{ml}$ of solution of either $\mathrm{HCl}$, deionized water or PBS. The released concentration was determined spectrophotometrically at $264 \mathrm{~nm}$ (corrected for release of carotene and background absorption via subtraction of the absorbance at $280 \mathrm{~nm}$. The dissolution of ibuprofen from commercial Ipren tablet was investigated as control in the same media.

\section{Results and discussion}

Preparation of calcium carbonate in the form of nanoparticles is a broadly recognized challenge. In our study, we initially attempted to decrease the size and improve uniformity of the particles via modification of the conditions of co-precipitation reactions in aqueous media. Standard precipitation, on stirring with a magnetic stirrer $(1600 \mathrm{rpm})$, even with rather diluted solutions of the reactant salts provided particles with sub-micrometer size and rather broad size distribution. Using high-speed mechanical stirrer and gas flow induced precipitation decreased the particles size, especially on addition of dopants and less polar alcohols, ethanol or $n$-propanol, as co-solvents (as revealed by XRD and NTA, see Figs. 1 and 2).

The aggregation in solution results in striking variation in hydrodynamic sizes as seen in Fig. $2 \mathrm{~A}$ (some concentration of the primary particles and minor aggregates are present, but the dominating size is over $300 \mathrm{~nm}$ ).

Addition of dopant cations, $\mathrm{Mg}^{2+}$ and $\mathrm{Fe}^{3+}$ does not lead to a decrease in the size of the primary particles ( $80 \mathrm{~nm}$ in average, see Fig. 1), but evidently decreases the hydrodynamic size of the aggregates in solution to between 100 and $200 \mathrm{~nm}$. Applying the

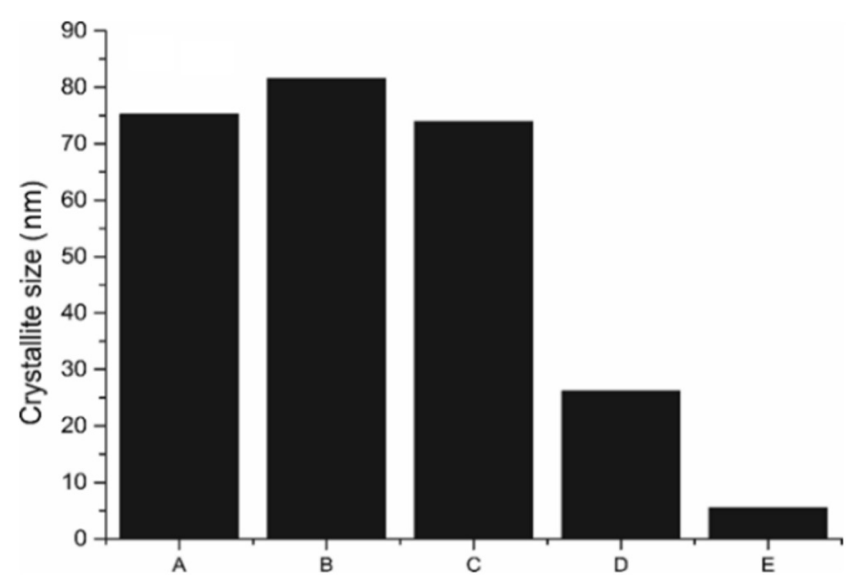

Fig. 1. Average size of calcium carbonate nanoparticles synthesized by different methods as measured by powder diffraction (Sherrer calculations). A: Standard precipitation. B: MgFe-doped through standard precipitation. C: MgFe-doped and with albumen surfactant through gas-sol-liquid. D: Mg-Fe doped gas-sol-liquid precipitation (Mg:Fe:Ca = 2:1:1 for B;C and D). E: Sol-gel synthesis.

solution of calcium hydroxide following the modified methodology proposed by Baroum et al. [35] resulted in the particles averaging about $75 \mathrm{~nm}$ in size (Fig. 1) and broad variation in hydrodynamic sizes spread between $75 \mathrm{~nm}$ (the primary particle size) and ca. $400 \mathrm{~nm}$ (Fig. 2C).

When the reaction was carried out between calcium hydroxide and carbon dioxide gas in $1 \%$ protein albumen solution, well known to adsorb onto calcium carbonate [42], it resulted in ca. $70 \mathrm{~nm}$ crystallite size (Fig. 1C), however with relatively monodisperse hydrodynamic size in suspension with a maxima around $200 \mathrm{~nm}$ in water (Fig. 2C). The same reaction in absence of the protein surfactant produced smaller particles with about $25 \mathrm{~nm}$ crystallite size but polydispersed hydrodynamic size in water with several maxima between 40 and $500 \mathrm{~nm}$ (Fig. 2D).

Carrying out the reaction in a polar medium containing water did not deliver small size nanoparticles, i.e. below ten $\mathrm{nm}$ in size. That is generally known to be produced as a result of nucleation of inorganic salts in organic media, the sol-gel process for metalderived materials [43]. We have therefore carried out precipitation of $\mathrm{CaCO}_{3}$ from an ethanol solution of calcium ethoxide $\left(\mathrm{Ca}(\mathrm{OEt})_{2}\right)$ in dry ethanol with carbon dioxide gas in ambient atmosphere (see Scheme 1).

The size of the nuclei of ionic solids, formed in anhydrous organic solvents, is commonly limited to a few $\mathrm{nm}$, and the Ostwald ripening phenomena are suppressed (as a consequence of extremely low solubility of these solid materials in organic solvents). The reaction products form as colloid solutions (sols) and undergo gelation over time. This phenomenon was clearly observed during the formation of $\mathrm{CaCO}_{3}$ in the present case. The size of the primary particles from TEM measurements (Fig. 3) was a couple to twelve $\mathrm{nm}$ with a clearly dominating fraction of five $\mathrm{nm}$ in size. Even the size of the particles in the initial sol determined by NTA was distinctly uniform (Fig. 2E) with the maximum under ten nm, actually below the detection limit of the instrument.

When transferred into aqueous medium, even just via dilution of the initial sol by water, the particles aggregate rather strongly, which results in a broad spectrum of sizes with several pronounced maxima from below 100 to over $500 \mathrm{~nm}$ (Fig. 2 F). The drying of the gels results in even stronger aggregation, as seen in SEM images (Fig. 4). The primary particles gather into hierarchical structures with ovoid assemblies of approximately $20-50 \mathrm{~nm}$ in size (Fig. 4D-E) aggregated into micron sized particles (Fig. 4B-C). This hierarchy is commonly observed in metal oxide sol-gel materials 

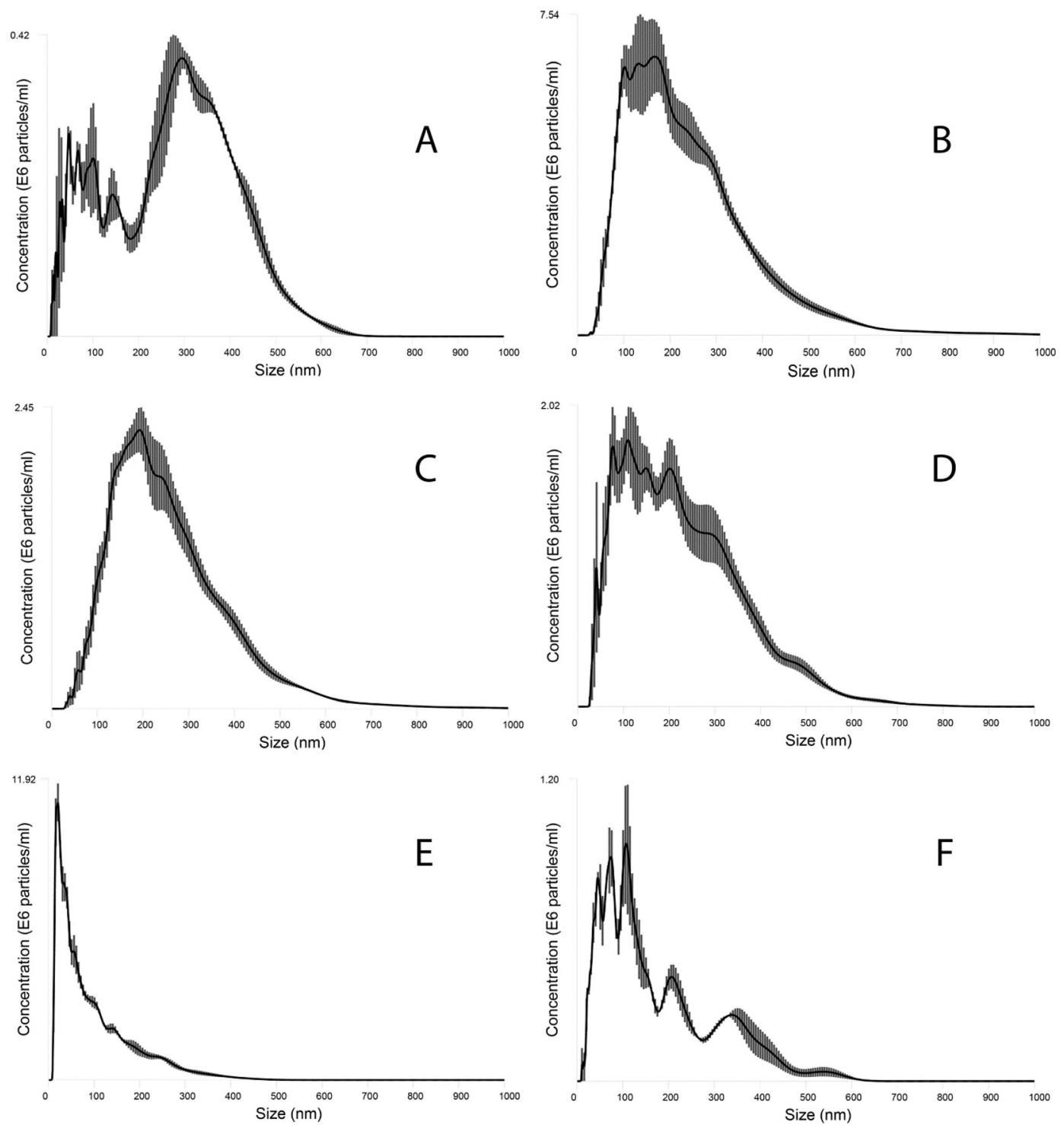

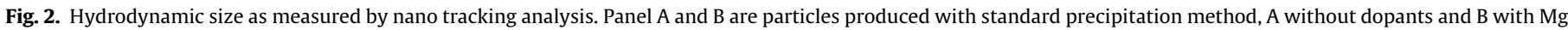

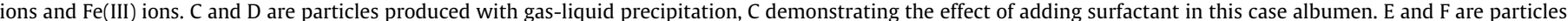
produced with sol-gel method, $\mathrm{E}$ as produced in ethanol and $\mathrm{F}$ after centrifugation substituting the ethanol with water. The error is shown around the line, $\mathrm{n}=4$.

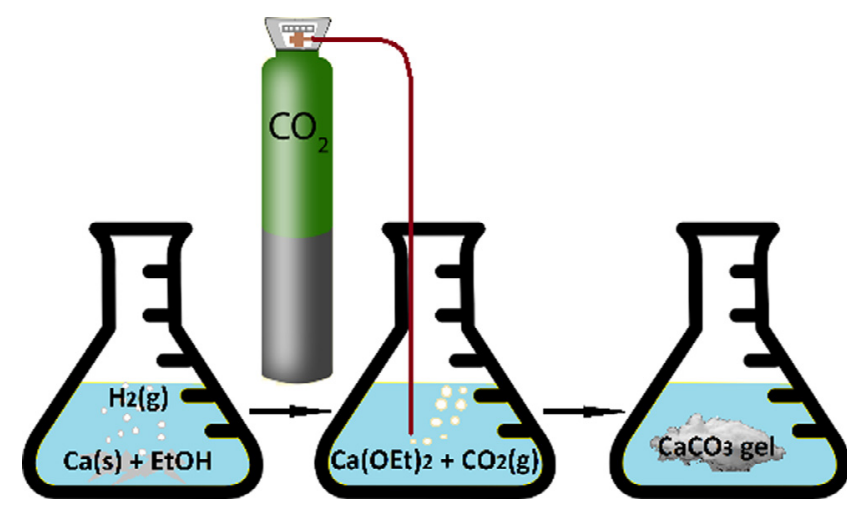

Scheme 1. Sol-gel synthesis of calcium carbonate.

[25]. The hydrodynamic size of particles as measured by DLS showed a similar pattern as NTA, namely a major growth in size following centrifugation and transfer to aqueous suspension
(Fig. $\mathrm{S} 1 \dagger$ ). The nitrogen adsorption was only measured on centrifuged gel material washed with ethanol, hence the rather small Brauner-Emmet-Teller (BET) surface of $22 \mathrm{~m}^{2} / \mathrm{g}$ (Table $\mathrm{S} 1 \dagger$ ) is not surprising. The aggregates were rather large, $3600 \pm 2200 \mathrm{~nm}$ as measured when re-dispersed into water, and they developed dense constructions on the surface of the aggregates; a common feature of xerogels obtained in sol-gel synthesis of inorganic salts, for example, metal oxides [44]. The zeta potential of the sol-gel synthesized $\mathrm{CaCO}_{3}$ nanoparticles was measured to $282 \mathrm{mv}$ in ethanol and $274 \mathrm{mv}$ in water, however the apparent zeta potentials showed a difference in that it was higher and exclusively positive in ethanol while in water the zeta potential showed a wider distribution from plus 50 to minus 80 which explains aggregation (Fig. $\mathrm{S} 2 \dagger$ ) In the XRD pattern of the sol-gel $\mathrm{CaCO}_{3}$ (Fig. S3†), it can be seen that the diffraction of the small particles result in extremely broad peaks and that the pattern is consistent with calcite.

The purpose of developing very small and monodisperse $\mathrm{CaCO}_{3}$ particles, was to obtain a matrix for encapsulation and release of hydrophobic and poorly water soluble components, such as, for example, anti-cancer drugs or pesticides. The aim of such applica- 


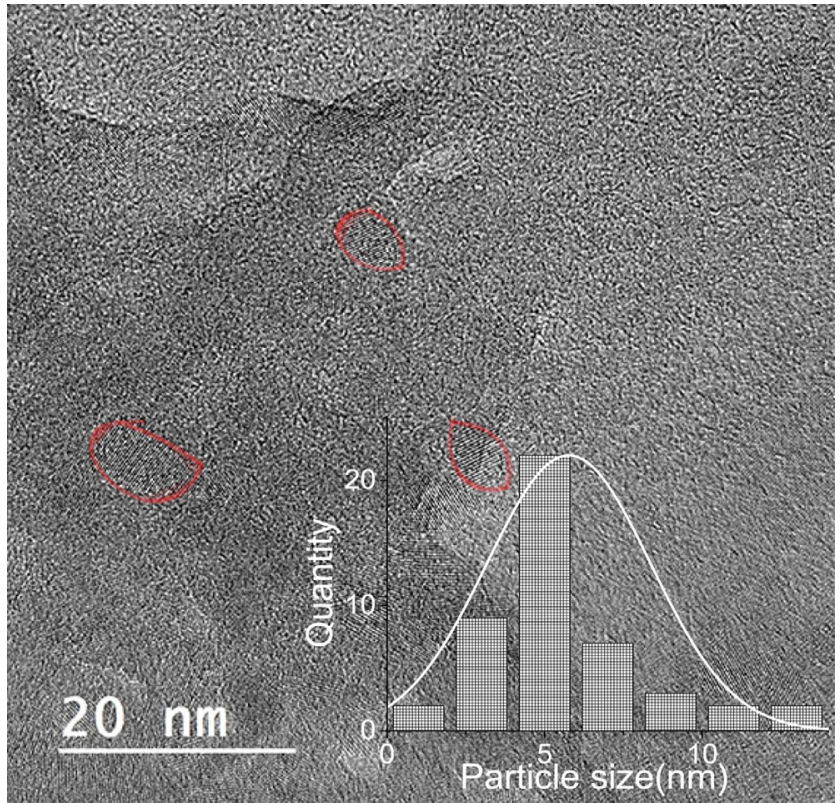

Fig. 3. Transmission electron micrograph of calcium carbonate particles, produced by sol-gel method, on carbon film. Individual particles that have the crystal lattice aligned with electron beam are marked by red circles. These are examples from a total of 46 particles that have been selected and measured with Gatan Digital Micrograph software. The inserted distribution plot shows the measured size of 46 individual particles from several images.

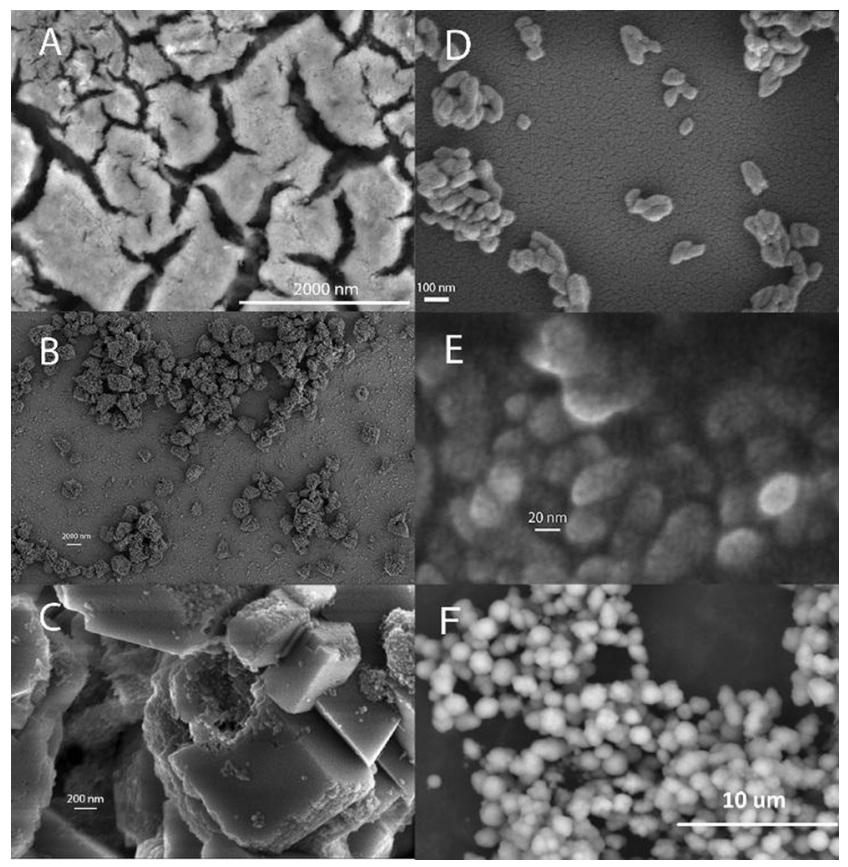

Fig. 4. SEM images of $\mathrm{CaCO}_{3}$ nanoparticles. (A) Gel formed by drying the mother liquor directly on to carbon tape and imaged at low magnification, scale bar $2000 \mathrm{~nm}$, (B-E) the same material centrifuge washed with ethanol and consequently dried and imaged at higher magnification, showing a hierarchical structure, scale bars are 2000, 200,100, and 20 respectively, (F) microparticles produced by precipitation in aqueous medium on addition of $1 \%$ albumen surfactant.

tion would be to incorporate the content in the form of preferentially amorphous nanoparticles within a composite and offer an opportunity for their release into a (colloid) solution upon dissolution in aqueous medium. Calcium carbonate has already been pro- posed as a drug carrier for its biocompatibility and $\mathrm{pH}$-sensitivity, especially for cancer treatment [8-11].

The inter-cellular environment of a cancer tumour becomes acidic, mostly due to excretion of lactic acid [45,46]. Lactic acid has a $\mathrm{pK}_{\mathrm{a}}$ of 3.86 so a tumour can become quite acidic in biological terms. There are hopes of development of clinical methods for measuring tumour $\mathrm{pH}$ to verify efficacy of the targeting and the drug before administration $[47,48]$. Although, it is known that cancer tumours do acidify and this can be utilised for targeted delivery. Any insoluble drugs delivered orally will benefit from having ultra-fine $\mathrm{CaCO}_{3}$-particles as drug delivery matrix.

In order to obtain a model nanocomposite, to investigate matrix properties, we introduced $\beta$-carotene dissolved in toluene, into the initial calcium ethoxide solution in the synthesis of sol-gel $\mathrm{CaCO}_{3}$. The toluene solution is diluted in the reaction medium without precipitation of highly hydrophobic $\beta$-carotene that becomes uniformly incorporated into the forming inorganic colloid. The drying of the composite gel produced spherical aggregates with average size about $200 \mathrm{~nm}$ (varying in the range $50-300 \mathrm{~nm}$ ). They have a complex hierarchical structure, consisting of smaller spheres as seen from TEM (Fig. 5).

The size of the primary $\mathrm{CaCO}_{3}$ particles in the composite is the same as in the pure xerogel of the salt. It is important to mention that formation of a nanocomposites, results in a minor decrease in crystallinity for the $\mathrm{CaCO}_{3}$ matrix and in complete disappearance of the diffraction peaks of the carotene itself, thus indicating that

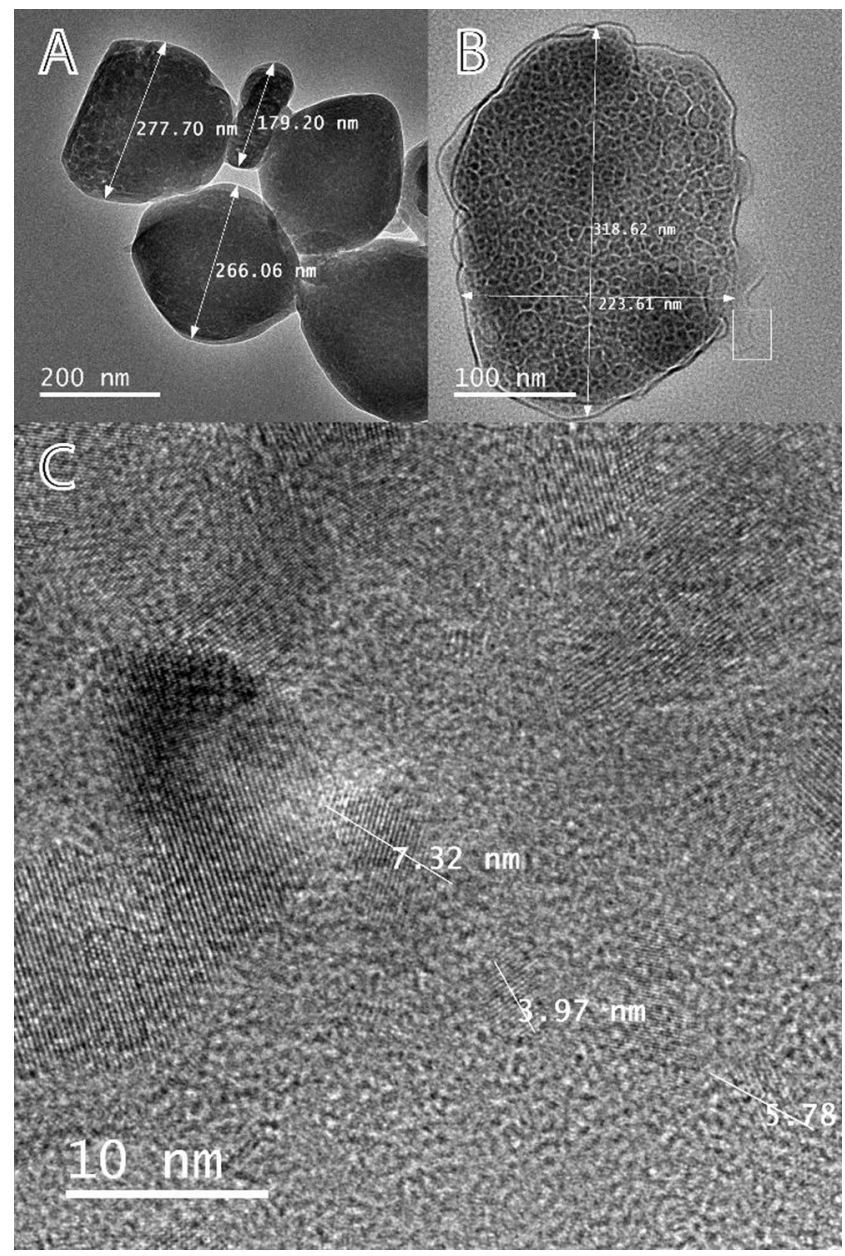

Fig. 5. HRTEM images of $\beta$-carotene loaded nanoparticles with increasing magnification from A-C. In panel B a small rectangle annotates the area where the image in the panel $\mathrm{C}$ is taken. 
the aim in producing small and amorphous particles of the hydrophobic constituent was successfully achieved (Fig. 6). The peaks of the $\mathrm{CaCO}_{3}$ diffraction pattern are extremely broad, but can be attributed to the calcite phase (Fig. S3). The HRTEM analysis is in agreement with calcite presence, as at least majority of the crystals has observed distances between fringes of $0.3 \mathrm{~nm}$.

It is important to note that the HRTEM study has a pronounced intrusive character on the crystal structure during investigations as the crystallinity increased under the electron beam during the time of the observation and became fully visible when carotene was destroyed under the electron beam.

The morphology and structure of the surface for the obtained nanocomposite were investigated by AFM technique. The hierarchical structure could clearly be traced in the surface features, showing protruding spherical aggregates of the primary particles (see Fig. 7). In the phase image, sensitive to the mechanical aspects of the cantilever interaction with the sample, it is easy to notice both the brighter spots probably originating from crystalline hard $\mathrm{CaCO}_{3}$ nanocrystals as well as the dark spots of softer material, indicating the surface carotene particles. Both features have sizes between 3 and $8 \mathrm{~nm}$. The general appearance of the material resembles that observed for, recently reported, $\mathrm{CaCO}_{3}$ polymer composite but the sizes of the grains are much smaller in our case [49].

The amount of incorporated $\beta$-carotene was possible to follow by TGA. It confirmed again that the produced material was $\mathrm{CaCO}_{3}$, thermally decomposing above $650{ }^{\circ} \mathrm{C}$ into $\mathrm{CaO}$; a process completed in this case at about $730^{\circ} \mathrm{C}$, which is a strikingly low temperature for this process. Commonly the thermal decomposition of $\mathrm{CaCO}_{3}$ starts around 800 and finishes at $900{ }^{\circ} \mathrm{C}$ for micro powders [50]. This property indicates that there are quantum confinement effects that affects the stability of the nano calcite particles. It was also shown that the amount of $\beta$-carotene loaded onto the $\mathrm{CaCO}_{3}$ matrix could be quantified by TGA as it occurred in the well-defined lower temperature interval $110-380^{\circ} \mathrm{C}$ (Fig. S4 $\dagger$ ).

Infrared spectroscopy revealed that the $\mathrm{CaCO}_{3}$ with calcite structure with absorbance peak maxima at 875 and $1483 \mathrm{~cm}^{-1}$ was produced, although an absorbance peak at $3645 \mathrm{~cm}^{-1}$ indicated the presence of coordinated $\mathrm{OH}$-groups, belonging either to adsorbed ethanol or to residual hydroxide impurity. Only a little change in the FTIR spectra of the $\mathrm{CaCO}_{3}$ particles occurs when they are loaded with $\beta$-carotene. When compared to a mechanical mixture of bulk calcite and $\beta$-carotene there is very little change except that a vibration around $1078 \mathrm{~cm}^{-1}$ is not present in the bulk. This could be explained by the nano size of calcite that could allow for umbrella mode vibration of the carbonate (see Fig. 8) [51].

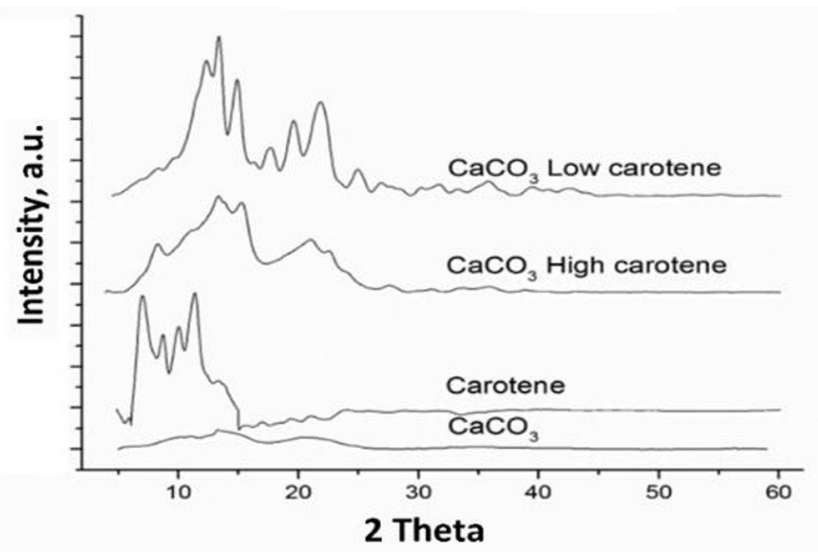

Fig. 6. X-ray powder diffraction patterns of sol gel $\mathrm{CaCO}_{3}$ and its composites with carotene and carotene alone.
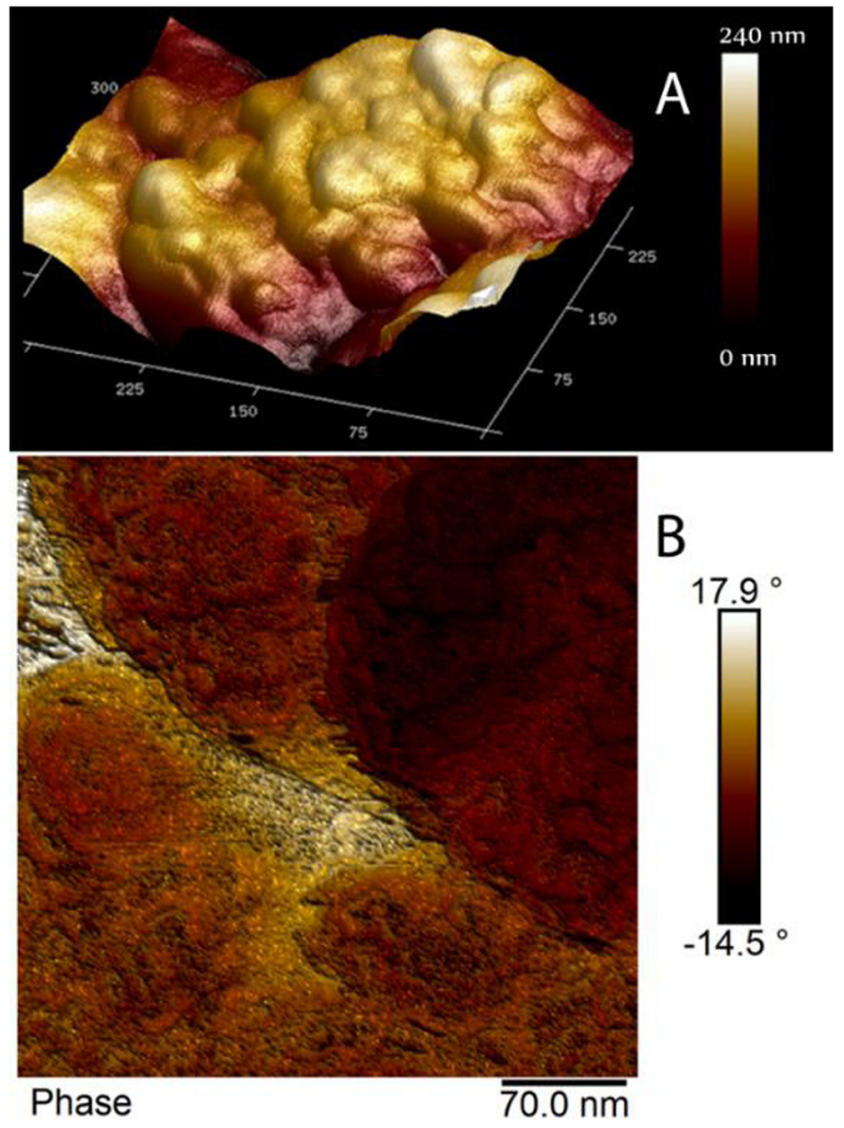

Fig. 7. Atomic force microscope images of the $\mathrm{CaCO}_{3}$-carotene nanocomposite surface: 3D-morphology (A) and phase characteristics related to mechanical strength and adhesion (B).

The release of carotene from the matrix was investigated in acidic environment. It was strongly dependent on both the $\mathrm{pH}$ of the medium and the content of incorporated carotene apparently influencing the hydrophobicity of the material. We found that maximum amount of $\beta$-carotene loading into the $\mathrm{CaCO}_{3}$ matrix to be about 20 weight per cent, above that, the resulting powder becomes too hydrophobic to be easily dispersed in aqueous solution. The dissolution seemed to be instantaneous in acid environment at $\mathrm{pH}=1.0$ but in water with $\mathrm{pH} 5.5$ a rather slow release of carotene was observed. The product obtained after release of carotene at lower pH was an almost clear colloid (Fig. 9, Fig. S5 $\dagger$ and ESI $1 \dagger$ ) with a bright red colour. Coagulation became visible as aggregation and precipitation of the hydrophobic phase between 5 and $8 \mathrm{~h}$ after the release indicating that the produced nanocomposite was capable of releasing non-aggregated particles of the hydrophobic load into the aqueous phase. The released colloid was easily extracted by a non-polar solvent and over time carotene was lost in acid environment, probably due to oxidation even though the samples were kept in darkness at seven degrees Celsius (Fig. S6†). When the samples were vortexed the red colour in the aqueous phase disappeared; also the aqueous solution became much clearer when $\mathrm{pH}$ was low (Fig. $\mathrm{S} 7 \dagger$ ).

It appeared interesting to investigate the effects of matrix hydrophobicity introduced by addition of $\beta$-carotene and also the influence of $\mathrm{pH}$ on the release of ibuprofen - a well-known painkiller drug, possessing rather low solubility at acidic conditions, hindering its uptake in per-oral ordination [52]. We have studied the release in hydrochloric acid at $\mathrm{pH}=2$ modelling the environment in the stomach, and in PBS solutions - a traditional model for blood medium. 


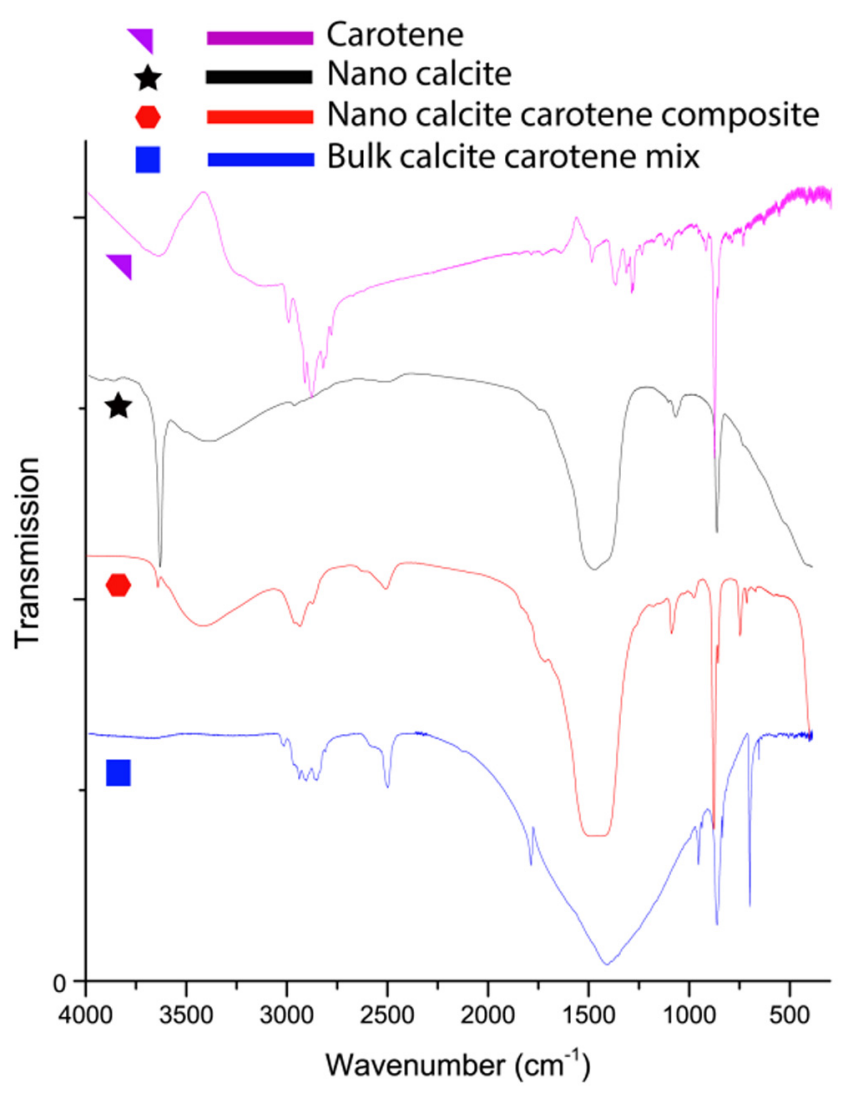

Fig. 8. FTIR spectrum of calcium carbonate nanoparticles produced by sol-gel synthesis with and without $\beta$-carotene incorporated. Also included are $\beta$-carotene alone and a mechanical mixture of bulk calcium carbonate and $\beta$-carotene.

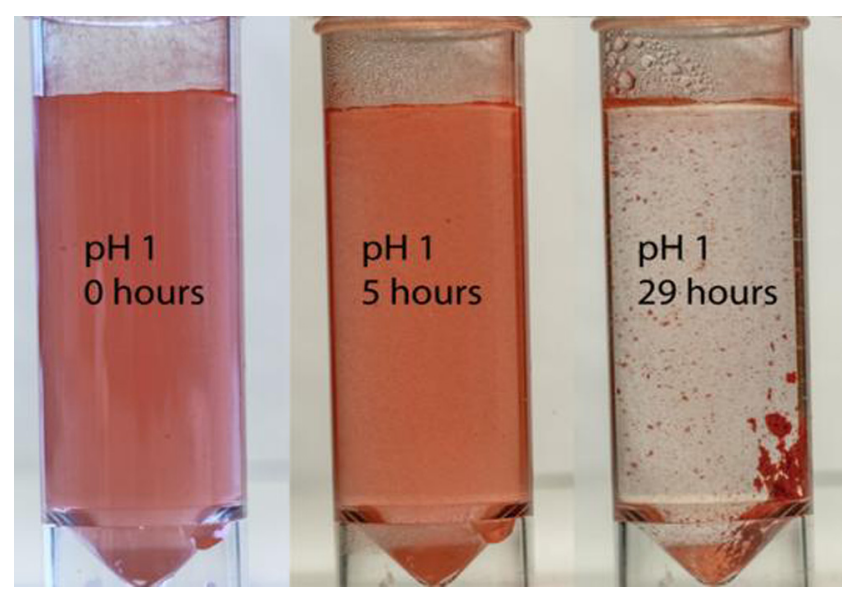

Fig. 9. Coagulation of $\beta$-carotene after release from $\mathrm{CaCO}_{3}$ matrix over time by visual observation.

Interestingly, in both cases the release of ibuprofen was achieved at the same level as in solutions saturated in basic conditions (see Fig. 10). The reaction with PBS was associated with release of $\mathrm{CO}_{2}$ gas and resulted in precipitation of poorly soluble $\mathrm{CaHPO}_{4}$ salt. It had shorter induction period, which is quite expected as the reaction is heterogeneous in this case. Application of a matrix containing $2 \mathrm{wt} \%$ of $\beta$-carotene produced distinctly lower concentrations, which apparently varied in time as can be seen from Fig. 10B. The variation in ibuprofen concentration in solution can be explained by transformation of the matrix. This can supposedly be rationalized in the following scenario: first

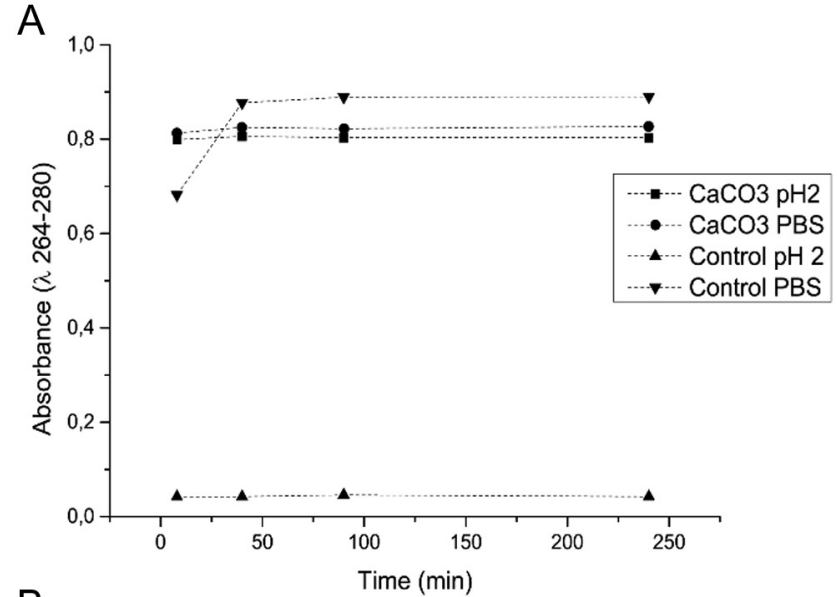

B

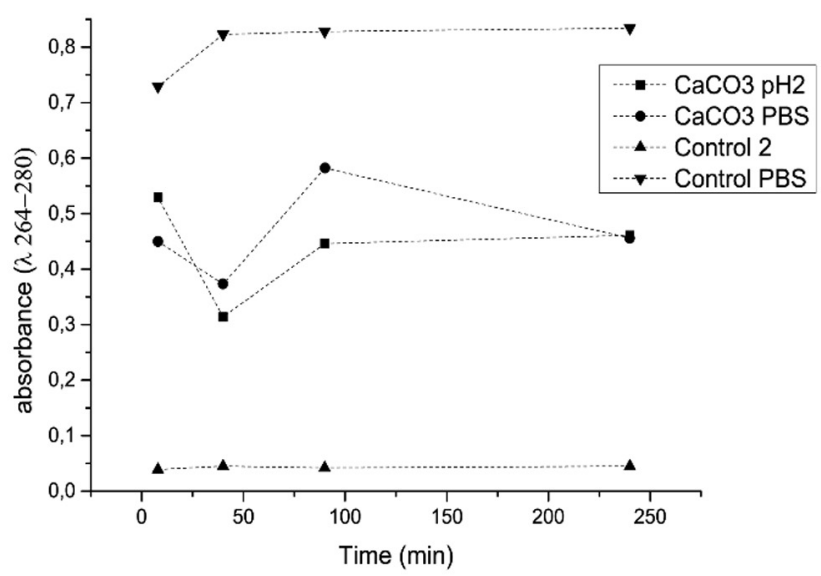

Fig. 10. Release of ibuprofen with time from pure $\mathrm{CaCO}_{3}$ matrix $(\mathrm{A})$ and from a matrix containing $2 \mathrm{wt} \% \beta$-carotene (B), both in comparison with dissolution of ibuprofen from a commercial painkiller tablet.

some surface adsorbed content was released supposedly quite quickly, then the exposed hydrophobic component re-adsorbed some of the released material. The process continued with further dissolution and partial re-adsorption and finally produced solutions with intermediate concentration of available medicine. This indicates that the facility and speed of release can be modulated by modifying the hydrophobicity of the matrix.

As the Sol-Gel method of synthesis successfully generates rather small particle size, there are other possible areas of application to consider. Concretes and composite materials are also interesting prospects to investigate for such small $\mathrm{CaCO}_{3}$ nanoparticles. Nano calcium carbonate is already used in paper production, since it is a cheap way of increasing strength, of lower quality cellulose fibre. Smaller particles will increase the surface to volume ratio, and hence increase the binding effect of the filler, leading to an even greater strength [53,54]. Similarly, $\mathrm{CaCO}_{3}$ is used on paper coatings for its white opaque qualities and a smaller particles size can lead to improvements, such as increased resolution of prints, higher strength and more gloss [55].

\section{Conclusions}

The proposed sol-gel synthesis of $\mathrm{CaCO}_{3}$ proved to create unprecedented size of $\mathrm{CaCO}_{3}$ nanoparticles with striking size uniformity. The obtained results clearly demonstrate their ability to incorporate hydrophobic components in a nanocomposite matrix converting them into amorphous nano sized particles, building 
stable colloids via release in acidic medium. Transfer of a sol produced in organic medium into water in the presence of albumen surfactant results in relatively uniform micro particles about $1 \mu \mathrm{m}$ size. The obtained materials show characteristics attractive for use in drug delivery and potentially also a variety of other industrial applications.

\section{Acknowledgements}

The authors would like to acknowledge Swedish grant funding agency FORMAS for funding of the project 2012-581 and the Swedish Research Council (Vetenskapsrådet) for the grant 2014-3938.

We would like to extend our gratitude to Ken Welch for the collaboration and providing access to the z-sizer instrument. Dr Cheuk-Wai Tai at Stockholm University is gratefully acknowledged for the help with TEM investigation of pure $\mathrm{CaCO}_{3}$ nanomaterial. Another thanks goes to MSL-lab Uppsala for giving us access to their facilities and also to Professor Klaus Leifer for his good advices. We are very grateful to Ahmed Baroum for sharing us his experience on nano calcium carbonate synthesis. One of the authors (VGK) would like to express his gratitude to SIGMA Clermont, France for the guest Professorship in 2015. The authors would like to express their gratitude to the EU COST Action MP1202 for creating a forum for contacts and discussion in the field of hybrid materials and interfaces.

\section{Appendix A. Supplementary data}

Supplementary data associated with this article can be found, in the online version, at http://dx.doi.org/10.1016/j.actbio.2017.05. 006.

\section{References}

[1] V.E. Bosio, M.L. Cacicedo, B. Calvignac, I. León, T. Beuvier, F. Boury, G.R. Castro Synthesis and characterization of $\mathrm{CaCO}_{3}$-biopolymer hybrid nanoporous microparticles for controlled release of doxorubicin, J. Colloid Interface Sci. B: Biointerafaces 123 (2014) 158-169.

[2] M.L. Cacicedo, K. Cesca, V.E. Valeria Bosio, L.M. Porto, G.R. Castro, Self-assembly of carrageenin- $\mathrm{CaCO}_{3}$ hybrid microparticles on bacterial cellulose films for doxorubicin sustained delivery, J. Appl. Biomed. 13 (2015) 239-248.

[3] W. Wei, G.H. Ma, G. Hu, D. Yu, T. McLeish, Z.G. Su, Z.Y. Shen, Preparation of hierarchical hollow $\mathrm{CaCO}_{3}$ particles and the application as anticancer drug carrier, J. Am. Chem. Soc. 130 (2008) 15808-15810.

[4] Y. Svenskaya, B. Parakhonskiy, A. Haase, V. Atkin, E. Lukyanets, D. Gorin, R. Antolini, Anticancer drug delivery system based on calcium carbonate particles loaded with a photosensitizer, Biophys. Chem. 182 (2013) 11-15.

[5] J.A. Thomas, L. Seton, R.J. Davey, C.E. DeWolf, Using a liquid emulsion membrane system for the encapsulation of organic and inorganic substrates within inorganic microcapsules, Chem. Commun. (2002) 1072-1073.

[6] Y. Ueno, H. Futagawa, Y. Takagi, A. Ueno, Y. Mizushima, Drug-incorporating calcium carbonate nanoparticles for a new delivery system, J. Control. Release 103 (2005) 93-98.

[7] V. Vergaro, P. Papadia, S. Leporatti, S.A. De Pascali, F.P. Fanizzi, G. Ciccarella, Synthesis of biocompatible polymeric nano-capsules based on calcium carbonate: a potential cisplatin delivery system, J. Inorg. Biochem. 153 (2015) 284-292.

[8] A. Shafiu Kamba, M. Ismail, T.A. Tengku Ibrahim, Z.A.B. Zakaria, A pH-sensitive, biobased calcium carbonate aragonite nanocrystal as a novel anticancer delivery system, Biomed. Res. Int. 2013 (2013) 1-10 587451.

[9] D. Zhao, C.J. Liu, R.X. Zhuo, S.X. Cheng, Alginate $/ \mathrm{CaCO}_{3}$ hybrid nanoparticles for efficient co-delivery of antitumor gene and drug, Mol. Pharm. 9 (2012) 2887 2893.

[10] G. Verreck, I. Chun, J. Rosenblatt, J. Peeters, A.V. Dijck, J. Mensch, M. Noppe, M E. Brewster, Incorporation of drugs in an amorphous state into electrospun nanofibers composed of a water-insoluble, nonbiodegradable polymer, J Control. Release 92 (2003) 349-360.

[11] J. Lu, M. Liong, J.I. Zink, F. Tamanoi, Mesoporous silica nanoparticles as a delivery system for hydrophobic anticancer drugs, Small 3 (2007) 1341-1346.

[12] K. Takagi, S. Okabe, The effects of drugs on the production and recovery processes of the stress ulcer, Jpn. J. Pharmacol. 18 (1968) 9-18.

[13] M.B. O'Connell, D.M. Madden, A.M. Murray, R.P. Heaney, L.J. Kerzner, Effects of proton pump inhibitors on calcium carbonate absorption in women: a randomized crossover trial, Am. J. Med. 118 (2005) 778-781.
[14] J.A. Levant, J.H. Walsh, J.I. Isenberg, Stimulation of gastric secretion and gastrin release by single oral doses of calcium carbonate in man, N. Engl. J. Med. 289 (1973) 555-558.

[15] P.N. Maton, M.E. Burton, Antacids revisited: a review of their clinical pharmacology and recommended therapeutic use, Drugs 57 (1999) 855-870.

[16] M.N. Portela da Silva, F. Espitalier, A. Nzihou, Precipitation process of calcium phosphate from calcium carbonate suspension, KONA Powder Particle J. 33 (2016) 219-227.

[17] M.H. Nielsen, S. Aloni, J.J. De Yoreo, In situ TEM imaging of $\mathrm{CaCO}_{3}$ nucleation reveals coexistence of direct and indirect pathways, Science 345 (2014) 11581162.

[18] S.T. Sun, D.M. Chevrier, P. Zhang, D. Gebauer, H. Cölfen, Distinct short-range order is inherent to small amorphous calcium carbonate clusters $(<2 \mathrm{~nm})$, Angew. Chem. Int. Ed. 55 (2016) 12206-12209.

[19] M. Farhadi-Khouzani, D.M. Chevrier, P. Zhang, N. Hedin, D. Gebauer, Water as the key to proto-aragonite amorphous $\mathrm{CaCO}_{3}$, Angew. Chem. Int. Ed. 55 (2016) 8117-8120.

[20] M. Kellermeier, P. Raiteri, J.K. Berg, A. Kempter, J.D. Gale, D. Gebauer, Entropy drives calcium carbonate ion association, ChemPhysChem 17 (2016) 35353541.

[21] C. Rodríguez-Navarro, E. Ruiz-Agudo, J. Harris, S.E. Wolf, Nonclassical crystallization in vivo et in vitro (II): nanogranular features in biomimetic minerals disclose a general colloid-mediated crystal growth mechanism, J. Struct. Biol. 196 (2016) 260-287.

[22] M. Kitamura, Crystallization and transformation mechanism of calcium carbonate polymorphs and the effect of magnesium ion, J. Colloid Interface Sci. 236 (2001) 318-327.

[23] B.L. Cushing, V.L. Kolesnichenko, C.J. O'Connor, Recent advances in the liquidphase syntheses of inorganic nanoparticles, Chem. Rev. 104 (2004) 38933946.

[24] K. Murai, T. Kinoshita, K. Nagata, M. Higuchi, Mineralization of calcium carbonate on multifunctional peptide assembly acting as mineral source supplier and template, Langmuir 32 (2016) 9351-9359.

[25] G.A. Seisenbaeva, V.G. Kessler, Precursor directed synthesis - "molecular" mechanisms in the Soft Chemistry approaches and their use for template-free synthesis of metal, metal oxide and metal chalcogenide nanoparticles and nanostructures, Nanoscale 6 (2014) 6229-6244.

[26] G.A. Seisenbaeva, G. Daniel, J.M. Nedelec, V.G. Kessler, Solution equilibrium behind the room-temperature synthesis of nanocrystalline titanium dioxide, Nanoscale 5 (2013) 3330-3336.

[27] K. Welin-Berger, B. Bergenståhl, Inhibition of Ostwald ripening in local anesthetic emulsions by using hydrophobic excipients in the disperse phase, Int. J. Pharm. 200 (2000) 249-260.

[28] N.A. Kotov, Practical aspects of self-organization of nanoparticles: experimental guide and future applications, J. Mater. Chem. 21 (2011) 16673-16674.

[29] A.U. Badnore, A.B. Pandit, Synthesis of nanosized calcium carbonate using reverse miniemulsion technique: comparison between sonochemical and conventional method, Chem. Eng. Proc.: Process Intensific. 98 (2015) 13--21.

[30] J. Jiang, J. Liu, C. Liu, G. Zhang, X. Gong, Roles of oleic acid during micropore dispersing preparation of nano-calcium carbonate particles, Appl. Surf. Sci. 257 (2011) 7047-7053.

[31] G. Montes-Hernandez, A. Fernandez-Martinez, L. Charlet, D. Tisserand, F. Renard, Textural properties of synthetic nano-calcite produced by hydrothermal carbonation of calcium hydroxide, J. Cryst. Growth 310 (2008) 2946-2953.

[32] S.H. Sonawane, S.P. Gumfekar, S. Meshram, M.P. Deosarkar, C.M. Mahajan, P. Khanna, Combined effect of surfactant and ultrasound on nano calcium carbonate synthesized by crystallization process, Int. J. Chem. Reactor Eng. 7 (2009) 1542-6580.

[33] G. Toprak, S.D. Alici, E. Ulkeryildiz, S.K. Ozdemir, E. Ozdemir, Production of nano calcite, Abstr. Pap. Am. Chem. Soc. (2012) 244.

[34] A. Barhoum, G. Van Assche, A.S.H. Makhlouf, H. Terryn, K. Baert, M.P. Delplancke, S.M. El-Sheikh, H. Rahier, A green, simple chemical route for the synthesis of pure nanocalcite crystals, Cryst. Growth Des. 15 (2015) 573-580.

[35] Y. Guo, F. Wang, J. Zhang, L. Yang, X. Shi, Q. Fang, X. Ma, Biomimetic synthesis of calcium carbonate with different morphologies under the direction of different amino acids, Res. Chem. Intermed. 39 (2013) 2407-2415.

[36] S.H. Sonawane, S.R. Shirsath, P.K. Khanna, S. Pawar, C.M. Mahajan, V. Paithankar, V. Shinde, C.V. Kapadnis, An innovative method for effective micro-mixing of $\mathrm{CO}_{2}$ gas during synthesis of nano-calcite crystal using sonochemical carbonization, Chem. Eng. J. 143 (2008) 308-313.

[37] G. Montes-Hernandez, A. Fernández-Martínez, L. Charlet, D. Tisserand, F. Renard, Textural properties of synthetic nano-calcite produced by hydrothermal carbonation of calcium hydroxide, J. Cryst. Growth 310 (2008) $2946-2953$.

[38] A.R. Ibrahim, J.B. Vuningoma, X. Hu, Y. Gong, D. Hua, Y. Hong, H. Wang, J. Li, High-pressure gas-solid carbonation route coupled with a solid ionic liquid for rapid synthesis of rhombohedral calcite, J. Supercrit. Fluids 72 (2012) 78-83.

[39] J. Kawano, S. Maeda, T. Nagai, The effect of $\mathrm{Mg}^{2+}$ incorporation on the structure of calcium carbonate clusters: investigation by the anharmonic downward distortion following method, Phys. Chem. Chem. Phys. 18 (2016) 2690-2698.

[40] M. Vinoba, M. Bhagiyalakshmi, S.Y. Choi, K.T. Park, H.J. Kim, S.K. Jeong, Harvesting $\mathrm{CaCO}_{3}$ polymorphs from in situ $\mathrm{CO}_{2}$ capture process, J. Phys. Chem. C 118 (2014) 17556-17566. 
[41] N.Y. Turova, E.V. Turevskaya, V.G. Kessler, A.I. Yanovsky, Y.T. Struchkov, Chem. Commun. (1993) 21-23.

[42] J.P. Bernard, Z. Adrich, G. Montalto, A. De Caro, M. De Reggi, H. Sarles, J.C. Dagorn, Inhibition of nucleation and crystal growth of calcium carbonate by human lithostathine, Gastroenterology 103 (1992) 1277-1284.

[43] V.G. Kessler, G.I. Spijksma, G.A. Seisenbaeva, S. Håkansson, D.H.A. Blank, H.J.M. Bouwmeester, New insight in the role of modifying ligands in the sol-gel processing of metal alkoxide precursors. A possibility to approach new classes of materials, J. Sol-Gel Sci. Technol. 40 (2006) 163-179.

[44] P. Werndrup, M. Verdenelli, F. Chassagneux, S. Parola, V.G. Kessler, Powders and dense thin films of late transition metal oxide nanocomposites from structurally characterized single-source precursors, J. Mater. Chem. 14 (2004) 344-350.

[45] Y. Kato, S. Ozawa, C. Miyamoto, Y. Maehata, A. Suzuki, T. Maeda, Y. Baba, Acidic extracellular microenvironment and cancer, Cancer Cell Int. 13 (2013) 1-8.

[46] S.K. Parks, J. Chiche, J. Pouyssegur, PH control mechanisms of tumor survival and growth, J. Cell. Physiol. 226 (2011) 299-308.

[47] R. Van Sluis, Z.M. Bhujwalla, N. Raghunand, P. Ballesteros, J. Alvarez, S. Cerdán, J.P. Galons, R.J. Gillies, In vivo imaging of extracellular $\mathrm{pH}$ using ${ }^{1} \mathrm{H}$ MRSI, Magn. Reson. Med. 41 (1999) 743-750.

[48] F.A. Gallagher, M.I. Kettunen, S.E. Day, D.E. Hu, J.H. Ardenkjaer-Larsen, R. Zandt, P.R. Jensen, M. Karlsson, K. Golman, M.H. Lerche, K.M. Brindle, Magnetic resonance imaging of $\mathrm{pH}$ in vivo using hyperpolarized ${ }^{13} \mathrm{C}$-labelled bicarbonate, Nature 453 (2008) 940-943.

[49] N. Feoktistova, J. Rose, V.Z. Prokopović, A.S. Vikulina, A. Skirtach, D. Volodkin, Controlling the vaterite $\mathrm{CaCO}_{3}$ crystal pores. Design of tailor-made polyme based microcapsules by hard templating, Langmuir 32 (2016) 4229-4238.

[50] N.B. Singh, N.P. Singh, Formation of $\mathrm{CaO}$ from thermal decomposition of calcium carbonate in the presence of carboxylic acids, J. Therm. Anal. Calorim. 89 (2007) 159-162.

[51] C.R. Brazier, P.F. Bernath, Observation of gas phase organometallic free radicals: monomethyl derivatives of calcium and strontium, J. Chem. Phys. 86 (1987) 5918, http://dx.doi.org/10.1063/1.452476.

[52] C.K.S. Ong, P. Lirk, C.H. Tan, R.A. Seymour, An evidence-based update on nonsteroidal anti-inflammatory drugs, Clin. Med. Res. 5 (2007) 19-34.

[53] T. Nypelö, M. Österberg, J. Laine, Tailoring surface properties of paper using nanosized precipitated calcium carbonate particles, ACS Appl. Mater. Int. 3 (2011) 3725-3731.

[54] M. He, B.U. Cho, J.M. Won, Effect of precipitated calcium carbonate-cellulose nanofibrils composite filler on paper properties, Carbohydr. Polym 136 (2016 $820-825$.

[55] M.A. MacGregor, A review of the topographical causes of gloss variation and the effect on perceived print quality, J. Kor. Tec. Ass. Pulp Paper Ind. 32 (2000) $26-43$. 